\title{
Heidegger and the History of Words: Formative Aspect of the Destruction of Tradition
}

\author{
By Marcelo José Doro, Cláudio Almir Dalbosco \& Raísla Girardi Rodrigues
}

Abstract- This article presents the results of a hermeneutical investigation on the constant etymological incursions performed by Heidegger throughout his works. We will try to show, first, how the recovery of the history of words promoted by the philosopher is associated with a way of understanding and doing philosophy, which he called destruction (Destruktion) of tradition; then we will explore the pedagogicaleducational character that underlies this way of dealing with history and, more specifically, with language. We will argue in favor of the idea that by means of this way of proceeding, in this peculiar way for which Heidegger does philosophy, the loosening of dogmatic structures of interpretation of self and of the world is opportunistic and opens up for new possibilities of articulation of meaning (that is, projection of self and of the world as a whole). In the educational context, this destructive posture would have the important role of breaking both with dogmatic attitudes arising from immediate daily life and with metaphysical ideals linked to theoretical positions, both of which are opposed to the plurality of ways of being in today's society.

Keywords: heidegger. history of words. destruction. formation. education.

GJHSS-D Classification: FOR Code: 430199p

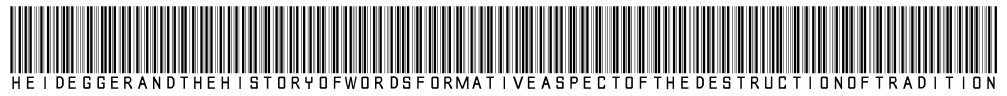

Strictly as per the compliance and regulations of:

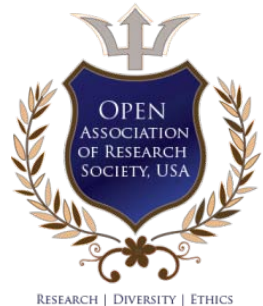

(C) 2021. Marcelo José Doro, Cláudio Almir Dalbosco \& Raísla Girardi Rodrigues. This research/review article is distributed under the terms of the Attribution-NonCommercial-NoDerivatives 4.0 International (CC BY-NC-ND 4.0). You must give appropriate credit to authors and reference this article if parts of the article are reproduced in any manner. Applicable licensing terms are at https:// creativecommons.org/licenses/by-nc-nd/4.0/. 


\title{
Heidegger and the History of Words: Formative Aspect of the Destruction of Tradition
}

\author{
Heidegger e a História das Palavras: O Aspecto Formativo da Destruição da \\ Tradição
}

\author{
Marcelo José Doro ${ }^{\alpha}$, Cláudio Almir Dalbosco ${ }^{\circ} \&$ Raísla Girardi Rodrigues ${ }^{\circ}$
}

Abstract- This article presents the results of a hermeneutical investigation on the constant etymological incursions performed by Heidegger throughout his works. We will try to show, first, how the recovery of the history of words promoted by the philosopher is associated with a way of understanding and doing philosophy, which he called destruction (Destruktion) of tradition; then we will explore the pedagogicaleducational character that underlies this way of dealing with history and, more specifically, with language. We will argue in favor of the idea that by means of this way of proceeding, in this peculiar way for which Heidegger does philosophy, the loosening of dogmatic structures of interpretation of self and of the world is opportunistic and opens up for new possibilities of articulation of meaning (that is, projection of self and of the world as a whole). In the educational context, this destructive posture would have the important role of breaking both with dogmatic attitudes arising from immediate daily life and with metaphysical ideals linked to theoretical positions, both of which are opposed to the plurality of ways of being in today's society.

Keywords: heidegger. history of words. destruction. formation. education.

Resumo- Este artigo apresenta os resultados de uma investigação hermenêutica acerca das constantes incursões etimológicas realizadas por Heidegger em suas obras. Tentaremos mostrar, primeiro, como a recuperação da história das palavras promovida pelo filósofo encontra-se associada a um modo de compreender e de fazer filosofia que ele chamou de destruição (Destruktion) da tradição; depois, interessa-nos explorar o caráter pedagógico-formativo inerente a esse modo de lidar com a história e, mais especificamente, com a linguagem. Argumentaremos a favor da ideia de que por meio desse modo de proceder, desse jeito peculiar pelo qual Heidegger faz filosofia, oportuniza-se o afrouxamento de estruturas dogmáticas de interpretação de si e do mundo e, com isso, abrem-se novas possibilidades de articulação de sentido (ou seja, de projeção de si e do mundo como um todo). No contexto educacional, essa postura destrutiva teria o importante papel de romper tanto com posturas dogmáticas oriundas do cotidiano imediato quanto com ideais metafísicos vinculados às posições teóricas,

Author a: Doutor em Educação pela Universidade de Passo Fundo (UPF), Brasil. Professor da Universidade de Passo Fundo.

e-mail:marcelodoro@upf.br

Author o: Doutor em Filosofia pela Universität Kassel, Alemanha (UNIKASSEL). Professor da Universidade de Passo Fundo (UPF), Brasil. e-mail: cadalbosco@upf.br

Author p: Doutoranda em Educação pela Universidade de Passo Fundo (UPF), Brasil. e-mail: raislag@gmail.com ambas avessas à pluralidade dos modos de ser na sociedade atual.

Palavras-chave: heidegger. história das palavras. destruição. formação. educação.

\section{INTRODUÇÃO}

rat eidegger é o filósofo que busca no encoberto novas possibilidades de pensar e ser no mundo. O que fica velado é tão importante para ele, quanto o que se mostra. Para um filósofo hermenêutico, as palavras não poderiam ficar de fora dessa sua concepção. Os leitores de Heidegger já estão familiarizados com suas frequentes incursões etimológicas. Mas, embora o filósofo demonstre exímio conhecimento da língua materna e das línguas clássicas da tradição greco-romana, a recuperação que ele promove da história das palavras não deve ser entendida como um mero exercício de erudição. Retornar ao étimo das palavras essenciais é, para ele, antes de tudo, uma forma de abrir caminhos para o pensamento.

Em sua obra principal, Ser e tempo, vemos o filósofo ressignificar o termo Dasein, usado até então para indicar a existência efetiva dos entes em geral, o qual passa a representar o modo de ser que é exclusivo do existente humano. Ele problematiza os componentes de Da-sein para mostrar que "ser" (sein) um humano significa construir a si mesmo a partir do "aí" (Da) de suas circunstâncias. Nessa nova perspectiva semântica, apenas o ser humano é Dasein, porque apenas esse ente adquire ser a partir de sua pertença a um mundo histórico específico. Outro movimento etimológico marcante de Ser e tempo é a reinterpretação, até certo ponto polêmica, de $\dot{\alpha} \lambda \dot{\eta} \theta \varepsilon \imath \alpha$. Destoando da tradução corrente do termo como verdade, Heidegger insiste que seu sentido literal é "desencobrimento". A intenção dessa releitura não é negar (ou rivalizar com) a concepção tradicional de verdade entendida como concordância, mas abrir caminho para outra forma de pensar o acontecimento fundamental da verdade, uma forma que permanece preservada na própria composição do termo grego ( $\alpha=$ negação; $\lambda \dot{\eta} \theta \omega=$ encoberto, oculto). Justamente essa possibilidade mais abrangente de pensar a 
verdade, que acabou se perdendo na tradução latina de $\dot{\alpha} \lambda \dot{\eta} \theta \varepsilon \imath \alpha$ por veritas, é o que Heidegger pretende resgatar por meio de sua incursão etimológica. ${ }^{1}$

Em escritos posteriores a Ser e tempo também são numerosos os exemplos desse modo de proceder. Convém mencionar a interpretação original que Heidegger faz de conceitos chave da filosofia grega, como $\lambda o ́ \gamma o \varsigma, \Phi v \sigma \iota \varsigma$ e $\tau \dot{\varepsilon} \chi v \eta$. Tais conceitos, revigorados em sua significação, passam a ocupar um lugar de destaque no desenvolvimento da segunda fase de seu pensamento. Igualmente significativo permaneceu sendo o envolvimento do filósofo com sua língua materna. De fato, com a mesma frequência com que o encontramos explorando os étimos gregos, também o vemos empenhar-se no resgate de sentidos esquecidos, na ressignificação e na composição de termos em língua alemã. A questão do ser, que no período de Ser e tempo foi pensada na proximidade com o Dasein, nessa fase posterior aparecerá ligada à Ereignis, um evento de produção de sentido que não pode mais ser pensado a partir do ser humano, mas que é, ao contrário, o próprio horizonte das possibilidades humanas, incluindo a do pensamento. No uso corrente da língua alemã, "Ereignis" significa evento, acontecimento. Mas Heidegger ouve aí a presença de "augen" (ver) e "eigen" (próprio) e usa a palavra para dizer algo muito mais profundo que um mero evento mundano. Uma vez substantivados, "Augen" e "Eigentlichkeit" podem significar ver com olhos próprios, no sentido de construir (formular) uma perspectiva autêntica ou se deixar orientar por tal perspectiva. É precisamente no quadro conceitual de sua filosofia, que Ereignis torna-se o termo para o acontecimento fundamental no qual o ser humano se apropria e é apropriado pelo ser, enquanto horizonte histórico de sentido que intermedia a compreensão que cada um tem de si e do mundo. ${ }^{2}$ E para expressar o

\footnotetext{
${ }^{1}$ Essa reinterpretação do termo grego $\dot{\alpha} \lambda \dot{\eta} \theta \varepsilon ı$ tem uma importância central na estruturação do pensamento heideggeriano. Para Stein (1983), é ela que confere originalidade à fenomenologia heideggeriana, cuja suposição de fundo é de que o essencial no ser humano e nas coisas tende ao disfarce ou ao ocultamento, cabendo ao método concentrar-se no "como" pelo qual isso que se oculta pode ser levado a revelação. Depois de Ser e tempo, segundo Stein, essa compreensão se radicaliza na obra de Heidegger, até o ponto de ele resumir com a palavra $\dot{\alpha} \lambda \dot{\eta} \theta \varepsilon ı \alpha$ o próprio objeto da filosofia: "A tarefa da filosofia deve ser analisada no interior do espaço criado pela tensão semântica resultante da relação que os dois pólos velamento-desvelamento mantêm entre si. O modelo binário mantémse, ainda que mudem os termos polares: ocultar-mostrar, esquecerlembrar, pensado-impensado, verdade-não-verdade, essência-nãoessência, dependendo sua força significativa sempre de certas variáveis: homem, ser, História da Filosofia, Era da Técnica" (STEIN, 1983, p. 114)

2 Para preservar esse sentido de apropriação presente no étimo alemão, as traduções portuguesas adotam expressões compostas: Ernildo Stein, em Conferências e escritos filosóficos, usa a formulação "acontecimento-apropriação" (HEIDEGGER, 1999); já Marco Antônio
}

momento atual de tal apropriação, Heidegger cunha o termo Gestell, a partir da substantivação do passado do verbo "stellen", que indica a ação de pôr, colocar, posicionar. Literalmente, Gestell significa aquilo que foi posto, colocado, posicionado.

No paradigma vigente, em que predomina a visão de mundo técnico-científica, o que está posto, previamente posicionado, é uma certa tendência de encarar todas as coisas e até mesmo o ser humano como estando disponível para a exploração e a manipulação. Essa tendência é o que constitui, para Heidegger (2006) a essência da técnica moderna. Assim, compreendida a partir de sua essência, a técnica é Gestell, ou seja, é a tendência de já se tomar tudo, de antemão, como mera disponibilidade. Trata-se de um movimento de expropriação que vem de fora, que força e torce as disponibilidades humanas, todas elas, na direção de um estar à disposição para o uso imediato, para a utilidade instrumental. Ora, é essa torção redutora que orienta o sentido instrumental e utilitarista da técnica contemporânea, que coíbe e encobre o sentido antropológico originário da técnica, como um modo prático-meditativo de agir no mundo, no qual práxis e poiésis dão-se as mãos para dar sentido existencial ao agir humano.

O sucesso ou o insucesso das investidas etimológicas de Heidegger, dessas que assinalamos e de tantas outras, não pode ser simplesmente medido com base em uma suposta correção histórica ou na mera coerência semântica de seu procedimento. Porque não é isso que está, fundamentalmente, em jogo. O que também não significa dizer, então, que se trata apenas da promoção de uma mística desenfreada das palavras, completamente destituída de propósito. O que se busca, ao que parece, é justamente afrouxar a tendência ao enrijecimento semântico da linguagem, que decorre de seu uso instrumental cotidiano. Essa "causa nobre" minimiza o fato de o filósofo, por vezes, manipular sutilmente a relação das palavras entre si a fim de abrir caminhos para a promoção de novas formas de pensar e agir.

Torna-se exemplar, nesse contexto, a aproximação questionável que o filósofo estabelece entre pensamento (Denken) e agradecimento (Danken), no curso O que significa pensar? (HEIDEGGER, 1964), por exemplo, serve ao esforço de extrapolar os limites minguados do pensar concebido como cálculo e representação. Esse tipo de pensamento, cunhado junto à tradição lógico-racional da filosofia, já não consegue pensar os fundamentos metafísicos dentro dos quais opera e, por isso, torna-se cego para suas próprias limitações. Por outro lado, o pensamento concebido como gratidão mantém-se aberto àquilo que

Casanova, na tradução de BeiträgezurPhilosophie (NomEreignis), adota a expressão "acontecimento apropriador" (HEIDEGGER, 2015). 
Ihe determina enquanto possibilidade e que é para ele uma dádiva: a manifestação do sentido, a compreensão do ser. Assim, mais do que o rigor etimológico, o que importa é a oportunidade de encontrar, junto ao trabalho com as palavras, novos caminhos para a reflexão e fazer de tal caminho um processo formativo e autoformativo. A etimologia, do modo como o filósofo a entende e a pratica, não está preocupada com o passado, mas com os significados ocultos (EILAND, 1982, p. 40). E, se em tudo isso há um interesse claramente formativo, como defendemos, então o esclarecimento etimológico torna-se indispensável, enquanto exercício de autoformação não só para o filósofo-escritor que resgata de maneira inovadora a origem dos conceitos, como, sobretudo, para o leitor que se dispõe a compreender paciente e meditativamente o exercício feito pelo filósofo-escritor. Nos vemos aqui, então, com uma "técnica" de escrita e leitura que exige, dado a sua profundidade, um outro tipo de "dis-posição", que obviamente não é mais aquele tipo de disponibilidade instrumental e utilitária que a pouco nos topamos.

Em síntese, o resgate heideggeriano da história das palavras, bem como a especulação relativa a essa história, seja no alemão, no grego ou em qualquer língua, tem uma dupla função metodológico-formativa: quebrar a rigidez conceitual que ameaça trancar o pensamento em um único viés investigativo e, com isso, abrir possibilidades formativas e autoformativas que vão além do exercício filológico e exegético, importante, mas insuficiente para dar conta da condição formativa do ser humano. Na base desse modo de proceder filosófico está o entendimento de que a potência do pensar depende de se manter a linguagem aberta para a possibilidade de articulação de novos sentidos. ${ }^{3}$ Dessa forma, a destruição da tradição, da qual Heidegger fala em Ser e tempo, pode ser entendida fundamentalmente como uma desconstrução da linguagem, que visa encontrar nas palavras algo além do que uma mera correspondência com o mundo, mas,

\footnotetext{
${ }^{3}$ Subjacente ao uso que Heidegger faz da etimologia está uma concepção de linguagem em relação a qual "palavras e coisas não são definidas adequadamente, nem como partículas materiais discretas nem como valores diferenciais vazios, mas como encontros multidirecionais que fogem de formulações metafísicas ou dualísticas" (EILAND, 1982, p. 40). Já em Ser e tempo, no § 34, vemos uma apresentação da linguagem intrinsecamente ligada à significância do mundo, que se articula com base em nosso envolvimento efetivo em contextos de práticas cotidianas. Nossas palavras e enunciados são compreendidos na medida em que apontam para um mundo de sentido compartilhado com aqueles com quem nos comunicamos. Ao mesmo tempo, é pela fala de uns com os outros que a estrutura significativa do mundo se mantém. Essa imbricação fundamental de linguagem, mundo e compreensão ganha mais força no pensamento posterior de Heidegger, quando a linguagem é apontada, na Carta sobre o humanismo, como "a casa do ser". Falar de uma "linguagem aberta" significa, nesse contexto, assumir a linguagem como campo dinâmico de articulação de novos sentidos para a manifestação do real. (Voltaremos a essa discussão no tópico seguinte).
}

também, que dê fundamentalmente sentido existencial ao mundo. É pela linguagem que a compreensão de mundo e a participação nele acontecem, uma vez que é "no mundo compartilhado, nos recursos de compreensão que a pessoa, o Dasein, vai lançar mão na sua interação com outros" (DE CASTRO, 2014, p. 87).

$\mathrm{Na}$ sequência, tentaremos mostrar, primeiro, como o trabalho de Heidegger com a história das palavras encontra-se associado a um modo de compreender e de fazer filosofia que o filósofo chamou de destruição (Destruktion). Depois, interessa-nos explorar o caráter pedagógico-formativo inerente a esse modo de lidar com a história e, mais especificamente, com a linguagem. Nossa hipótese é que nesse modo de proceder, nesse jeito peculiar pelo qual Heidegger faz filosofia, oportuniza-se o afrouxamento de estruturas dogmáticas de interpretação de si e do mundo e, com isso, abrem-se novas possibilidades de articulação de sentido (ou seja, de projeção de si e do mundo como um todo). O árduo trabalho destrutivo opera, metaforicamente, como uma pinça que remove o cisco do olho, abrindo a visão para ver com mais claridade o que antes esta turvado. No contexto educacional, essa postura destrutiva teria o importante papel de romper tanto com posturas enrijecidas oriundas do cotidiano imediato quanto com ideais metafísicos vinculados às posições teóricas, ambos avessos à pluralidade de modos de ser identificados na sociedade atual. Em síntese, a Destruktion filosófica, concebida formativamente, conduz ao reexame de crenças e à reordenação dos modos de viver. Em síntese, ela conduz, quando compreendida adequadamente, à transformação do sujeito que a ela se entrega, provocando sua própria autoformação.

\section{A Destruição da Tradição Como Método Filosófico}

O pensamento de Heidegger, apresentado em Ser e tempo, traz uma pesada crítica à tradição filosófica ocidental. No centro dessa crítica está a contestação da pretensão de se afirmar verdades absolutas. Desde Platão, passando por Descartes e chegando até Hegel e o positivismo, a filosofia tem sido marcada pela crença de que poderíamos atingir a verdade enquanto algo evidente e garantido. Essa demanda por uma verdade evidente e garantida coincide com a tentativa de escapar da contingência temporal, fato esse que levou a tradição a separar o ser (realidade) do tempo (transitividade). Há, já aqui, implicações importantes para a concepção de formação humana, visto que, por essa via tradicional, como afirma Rorty $(1999$, p. 63), "não teríamos mais de ter projetos, não teríamos de nos criar através da invenção e prossecução desses projetos". Ou seja, o 
sentido metafísico de verdade como uma evidência garantida e que pode ser apreendida pelo intelecto filosófico, termina por tornar preguiçosa a própria liberdade humana, gerando passividade e comodismo em relação às escolhas e decisões a serem tomadas. Quanto a isso, a filosofia de Heidegger pode ser entendida como um esforço para recapturar um sentido de contingência, de fragilidade e risco inerente a qualquer projeto humano, que aparece como uma conquista filosófica capital de Ser e tempo, quando a temporalidade enquanto historicidade é justificada como um dos principais existenciais do Dasein. Desde então, projetos ontológicos precisam estar imbricados com a historicidade humana e social, pondo em cheque, em última instância qualquer perspectiva essencialista de formação humana.

Contudo, esse tornou-se um sentido especialmente difícil de ser recapturado justamente por conta da associação instituída pela tradição filosófica entre o contingente e o meramente aparente. Nas palavras de Rorty (1999, p. 63-64): "Ao contrastar a poderosa realidade com a relativamente impotente aparência, e afirmar que é essencial contactar com a primeira, a nossa tradição sugeriu que 0 frágil e 0 transitório podem ser negligenciados com segurança". Essa posição mostra-se especialmente clara em relação à linguagem, onde se observa o esvaziamento da importância das palavras específicas que utilizamos. Assim,

Desde que a filosofia ganhou a sua querela com a poesia, é o pensamento que tem contado - a proposição, algo que muitas frases em muitas línguas exprimem igualmente bem. Quer uma frase seja escrita ou falada, quer contenha palavras gregas, palavras alemãs ou palavras inglesas, tal coisa, segundo a visão filosófica tradicional, não interessa grandemente. Pois as palavras são meros veículos para algo menos frágil e transitório que sinais e ruídos. Os filósofos sabem que o que interessa é a verdade literal, não uma escolha de fonemas, e não certamente as metáforas. O literal perdura e confere poder. O metafórico - aquilo que não podemos quer discutir quer justificar, aquilo para o qual não conseguimos encontrar sequer uma paráfrase incontroversa - é impotente. Passa e não deixa nenhum vestígio. (RORTY, 1999, p. 64)

Retenhamos o núcleo dessa passagem: ao ganhar a batalha contra a poesia, a filosofia instituiu a instância lógico-semântica da proposição como fonte exclusiva de sentido, relegando a metáfora e tudo o mais que gira ao seu redor, para o campo do sem sentido. Quando o sentido literal vence o metafórico, tudo se concentra na análise lógica do sentido proposicional, esquecendo-se, com isso, o sentido originário veiculado pela tradição. No entanto, isso se modifica radicalmente quando Heidegger afirma que "as palavras brotam dos significados", mas que "não são coisas dotadas de significados" (1986, p. 161). Ao mesmo tempo que expressam sentidos inerentes à um mundo, as palavras também participam da articulação desse sentido. Elas estão referidas ao próprio sentido do mundo como um todo. Não se pode, por isso, separar de um lado a realidade e de outro as palavras, como se estas fossem meros instrumentos para a representação daquela. $\mathrm{O}$ sentido disso que chamamos de realidade se abre ou se fecha a cada vez por meio das palavras que usamos. Essa é uma consequência necessária do fato de que as pessoas não criam novamente todas as suas palavras a cada geração. "Elas herdam a maioria das palavras de gerações anteriores. Aplicam-nas as suas experiências correntes. As palavras, em sua maioria, não emergem da experiência. As experiências são, ao menos em parte, vistas através de palavras e conceitos herdados" (INWOOD, 2002, p. XX). É por isso que, "de certo modo e em certa medida, o Dasein se compreende a si mesmo de imediato a partir da tradição" (HEIDEGGER, 1986, p. 20). Com isso, estão postas duas coisas importantes ao nosso tema: primeiro, a tradição é inegavelmente fonte de sentido, quer construtivo, quer destrutivo; e, segundo, dependendo do modo como é aprendida, evidencia-se mais um ou outro. De qualquer sorte, sem o trabalho metódico e paciencioso da Destruktion, e essa é a crença heideggeriana, tendencialmente a tradição opera como uma força encobridora.

O problema, contudo, é que esse envolvimento com a tradição, mediado pela linguagem, de início e na maioria das vezes se dá de um modo meramente raso e, precisamente por isso, nesse modo em que ela é recebida, passa a operar como uma força encobridora, não mais crítica, mas mistificadora. O legado da tradição fica a cargo das evidências superficiais mantidas no cotidiano, o que acaba obstruindo "a passagem para as 'fontes' originais, de onde as categorias e os conceitos tradicionais foram hauridos, em parte de maneira autêntica e legítima" (HEIDEGGER, 1986, p. 21). Isso quer dizer que, em geral, articulamos nossa compreensão do mundo e de nós mesmos a partir de uma base conceitual que não experienciamos em toda a sua extensão. Precisamente aqui surge a necessidade da destruição do acervo linguístico legado pela tradição e de sua atualização por meio do resgate crítico do sentido originário das possibilidades inerentes a ela. Então, como força metódico-formativa, a Destruktion auxilia na limpeza do terreno, preparando o solo para que germine o sentido originário esquecido dos conceitos, fazendo-os ganhar força esclarecedora, ao ter que se atualizarem para descobrir a atualidade e pertinências de problemas, visando buscar suas soluções possíveis.

A destruição age sobre o vocabulário essencial que a tradição hauriu de modo originário, mas que no uso posterior da linguagem foi incorporado de modo superficial. A destruição envolve, portanto, a recuperação da "certidão de nascimento" dos termos fundamentais de uma tradição, não simplesmente para 
relativizar suas perspectivas, mas para "definir e circunscrever a tradição em suas possibilidades positivas, e isso quer sempre dizer em seus limites" (HEIDEGGER, 1986, p. 22). Essa tarefa nada tem a ver com o aniquilamento ou dizimação da tradição cultural mais ampla e especificamente filosófica, mas, também, nem com a simples aceitação passiva de seu sentido originário. Uma compreensão equivocada desse tipo, induzida pelas línguas europeias, foi, segundo Gadamer, a responsável pela má recepção de Heidegger no mundo; ele esclarece, no entanto, que "para o sentimento linguístico daqueles anos, 'destruição' não significava de maneira alguma 'dizimação', mas tinha em vista uma desconstrução com uma meta segura: uma desconstrução das camadas sedimentadas que, por fim, outrora como hoje, não vêm ao encontro senão na língua realmente falada" (GADAMER, 2007, p. 29) ${ }^{4}$ Longe de reprimir e afastar a tradição, o que a destruição busca é, portanto, a sua valorização por meio do resgate da força histórica dos conceitos e noções legados por ela. "Trata-se de desconstrução para a liberação. A destruição volta-se contra o encobrimento e empreende a liberação daquilo que estava encoberto" (GADAMER, 2007, p. 99). Sob esse aspecto, Gadamer concebe a destruição como uma tarefa positiva a tal ponto de transforma-la em princípio fundamental de sua própria hermenêutica, concebendo-a nos termos específicos de uma prestação conceitual de contas. Ou seja, segundo ele, é indispensável à atividade de pensar o diálogo crítico com a tradição intelectual passada e tal diálogo assume o exemplo da Destruktion heideggeriana.

Voltando a Heidegger, somente em relação ao tempo presente é que a destruição pode repercutir negativamente: "a destruição [em sentido negativo] não se refere ao passado; a sua crítica volta-se para o 'hoje' e para os modos vigentes de se tratar a história [...]" (HEIDEGGER, 1986, p. 22-23). Isso quer dizer: o resgate do sentido mais originário dos termos elementares de nossa tradição abala a rigidez e o enrijecimento do vocabulário "naturalizado" que empregamos na articulação de nossa compreensão atual da realidade, podendo ser, nesse sentido, contrário ao nosso envolvimento atual com a tradição (se esse envolvimento for dogmático, por exemplo), mas não em relação ao que é legado por ela, onde sentidos ainda ocultos encontram-se sedimentados no cerne da origem das palavras, mostrando-se necessário um resgate destrutivo, um resgate que desvele novos horizontes de sentidos já ali cunhados. Nesse sentido, a tarefa destrutiva abre dupla

\footnotetext{
"A apresentação da "destruição" em termos de "desconstrução" é respaldada pelo próprio Heidegger no curso Os problemas fundamentais da fenomenologia (2012, p. 39), onde o filósofo faz uma ampla apresentação do método fenomenológico, considerando seus três momentos: redução, construção e destruição.
}

possibilidade formativa, interligada entre si: possibilita nosso retorno ao sentido originário dos conceitos de certas tradições intelectuais e, simultaneamente, desnaturaliza os aspectos dogmáticos de nossa visão de mundo envolvidos no uso congelado que fazemos de certos conceitos. Essa crítica destrutiva, que em princípio é dirigida por Heidegger diretamente às teorias filosóficas, pode ser estendida, ainda com maior vigor, para o âmbito da educação e o modo como a pedagogia contemporânea dialoga com as teorias educacionais passadas. Com isso, pode se tornar poderoso dispositivo de avaliação crítica de conceitos pedagógicos contemporâneos.

Demarcada a tarefa da destruição da tradição como um retorno ao passado para liberar o presente, a filosofia tem um importante papel a cumprir, visto que "[...] o ofício da filosofia é, em última instância, preservar a força das palavras mais elementares em que o Dasein se pronuncia, a fim de que elas não sejam niveladas à incompreensão do entendimento comum, fonte de pseudo-problemas" (HEIDEGGER, 1986, p. 220). Preservar a força das palavras mais elementares, impedir sua derrocada no uso superficial que delas se faz no senso comum... tal coisa não se justifica porque o sentido originário é mais verdadeiro, mas porque podemos visualizar com isso a transformação histórica de seu sentido e, consequentemente, o caráter metafórico de todo sentido. O fato de as palavras possuírem um sentido original revela, antes de tudo, seu caráter histórico. Elas são o índice de um modo determinado de experimentar o mundo, pelo que não convém usá-las ingenuamente como se tivessem um sentido literal. E, contudo, é bem assim que procedemos na maior parte das vezes, quando usamos as palavras como se fossem um instrumento habitual que se encontra disponível. Nesse uso fácil e frequente já não escutamos o que as palavras dizem, precisamente porque não temos a noção de sua origem e historicidade. Então, elas perdem a força mobilizadora que as liga à significância do mundo e que nos faz pensar. Para torná-las mais uma vez potentes, "precisamos escutá-las da maneira que um poeta o faz quando decide pôr uma num determinado lugar de um determinado poema. Ao escutarmo-las assim preservaremos o que Heidegger chama a sua 'força'. Escutá-las-emos da mesma maneira que escutamos uma metáfora pela primeira vez" (RORTY, 1999, p. 65). A desconstrução da tradição pode nos proporcionar isso: ouvir novamente a força metafórica das palavras e, com ela, descortinar novos horizontes de pensamento e ação. Em síntese, quando o sentido originário dos conceitos torna-se profundamente naturalizado, perdendo sua própria noção de historicidade, então, a força formativa da filosofia, com a contribuição direta de outras expressões culturais significativas, como a própria poesia, torna-se força crítica poderosa para a desnaturalização dos conceitos 
e dos aspectos petrificados de nossas visões de mundo (Weltanschauung).

Mas, por que deveríamos querer ouvir novamente a força metafórica das palavras? Porque precisamos reconhecer, em um ato de humildade, que a metáfora surge lá onde a linguagem filosófica e científica conhece seus próprios limites; ou seja, a metáfora nasce e se torna imprescindível para dizer o indizível da linguagem (FRANK, 1990). Quando queremos dizer algo de importante e não encontramos a força conceitual necessária, quando queremos explicar um fenômeno e ainda não temos a formulação teórica suficiente ou, enfim, quando topamos com o próprio inexplicável, precisamente aí é que recorremos à metáfora para dizer o que ainda está fora do alcance de nossa compreensão. Talvez, seja no âmbito educacional, mais precisamente da formação humana, que podemos perceber a emergência da força metafórica das palavras, sobretudo, em um contexto no qual a educação parece encontrar a solução mágica de todos os seus problemas na redução do ensino à aprendizagem dominada pela linguagem das competências. Na sequência, procuramos problematizar alguns aspectos formativos inerentes à postura da Destruktion filosófica.

\section{il. Caráter Formativo da Destruição da TRADIÇÃO}

O discurso da formação está ligado a uma longa tradição filosófico-pedagógica, que se origina com a Paideia grega, passa pela Humanitas latina e desemboca na Bildung alemã. Atualmente, observa Biesta (2002), o conceito de formação reúne as aspirações de todos aqueles que esperam ou reconhecem que a educação é mais do que a mera transmissão de competências e habilidades de uma geração para outra, que ela também tem algo a ver com o cultivo intenso do ser humano, com sua individualidade, enfim, com o "tornar-se e ser alguém" e isso exige que se retome, ao modo heideggeriano de uma Destruktion, alguns ideais esquecidos da longa e boa tradição educacional. Ora, foi precisamente na origem da vertente poética da tradição educacional ocidental, que Píndaro formulou, em um contexto epocal bem aristocrático, o grande ideal da Paideia, em sua fase inicial, afirmando que o ser humano (o nobre) precisa tornar-se aquilo que ele é, ou seja, descobrir em si mesmo as capacidades a serem desenvolvidas. Isso soa, como deixa entender o historiador educacional francês Henri-Irénée Marrou (1990, p. 72), uma crítica implícita aos embrionários estabelecimentos de ensino e a força coercitiva de fora para dentro que exerciam na formação da interioridade humana. Também é esse desejo de liberdade, do livre cultivo de todas as capacidades humanas, que movimentará, muito mais tarde, já no século XIX, a crítica aristocrática nietzschiana aos estabelecimentos do ensino alemão e que conduzirá o próprio Friedrich Nietzsche a colocar como subtítulo de sua autobiografia filosófica nada mais nada menos do que a expressão lapidar do poeta grego, vertida para o alemão: "wie man mird, was man ist", "como alguém se torna o que é" (NIETZSCHE, 1999).

Desse modo, na Modernidade, a formação que era até então, por influência da Alta Escolástica, pensada somente em relação ao seu conteúdo e à aquisição formalizada do mesmo, passou a considerar também o processo de constituição desse conteúdo e, de certo modo, a experiência formativa de todos os envolvidos no processo formativo. É nesse contexto que se deixa compreender a crítica pioneira que JeanJacques Rousseau empreende aos efeitos corruptores da educação bárbara sobre o mundo infantil, erguendo contra isso o credo pedagógico moderno de que educador e educando precisam ser tomados em seu próprio mundo e que, principalmente a criança, precisa ser tomada como criança (ROUSSEAU, 1992). A partir daí, como uma espécie de revolução copernicana no domínio da pedagogia, explodem os romances de formação e as autobiografias, como a nietzschiana recém citada e, pouco antes dela, a monumental De minha vida: Poesia e verdade (Aus meinem Leben: Dichtung und Wahrheit), de Johann Wolfgang von Goethe (GOETHE, 2017). O que há de comum em todas elas, inclusive engrossadas pelo caldo filosófico e formativo das Confissões rousseaunianas, é a exigência de se conceber a formação, quer seja como narrativa autobiográfica ou como relação pedagógica entre adulto e criança, entre professor e aluno, como processo de autoformação. $\mathrm{Na}$ busca pela autoformação, o que também está em jogo é a constituição da singularidade subjetiva do sujeito a partir de sua relação com a tradição cultural que é a sua própria tradição. Contudo, reside nessa busca o perigo de dois extremos: por um lado, o risco de o indivíduo ser completamente absorvido pelas forças culturais vigentes em seu mundo, perdendo sua autonomia e; por outro, o risco de ele, ao se manter alheio a tais forças culturais, privar a si mesmo de uma gama mais ampla de possibilidades de ser. O fato é que este duplo perigo impulsiona a autoconsciência educacional moderna a exercitar sua própria tarefa destrutiva, buscando resgatar suas origens para melhor compreender sua atualidade e a posição que ocupa nessa atualidade. ${ }^{5}$

O ideal moderno de formação, nos termos da Bildung clássica, representada por figuras como Kant, Goethe e Humboldt, pendia claramente para o lado de uma forte autonomia do indivíduo em relação à

\footnotetext{
${ }^{5}$ Isso se relaciona com aquilo que Jürgen Habermas denomina, a partir de outro contexto teórico, de autocertificação filosófica da modernidade (HABERMAS, 2000)
} 
realidade social. Hoje, como bem observa Goergen (2017, p. 450), "pendemos para o extremo oposto, na medida em que o homem abre mão de sua liberdade e se submete ao real, ao sistema". Para além dos extremos da formação pensada como máxima autonomia e como submissão às forças sócio-culturais, Goergen sugere pensar a formação como "relação dialética de ancoragem e superação" (2017, p. 450). Aqui, justamente, gostaríamos de inserir a contribuição formativa da destruição da tradição proposta por Heidegger.

A destruição, compreendida nos termos que a apresentamos no tópico anterior, representa ao mesmo tempo um retorno para o seio da tradição, da cultura, e também a possibilidade de sua transformação. Sem esse retorno, ou seja, sem a recuperação do sentido originário da visão de mundo vinculada às palavras que usamos fácil e frequentemente, não se alcança a perspectiva pela qual podemos reconhecer a historicidade da visão de mundo que molda nossa compreensão da realidade. E sem esse primeiro passo de reconhecimento da visão de mundo vigente, nossos projetos (éticos e políticos) nunca aparecerão exatamente como são, isto é: como projetos contingentes que dependem inteiramente de nossas escolhas e que, como tal, podem ser revisados, transformados ou mesmo abandonados. Contrariamente ao que pressupõe o senso comum, não é deixando a tradição para trás (esquecendo-nos do passado) que nos libertamos, mas antes por meio de sua correta apreensão. A desconstrução da tradição nos liberta em três sentidos distintos, embora complementares: a) na percepção do caráter histórico pelo qual se articula a nossa compreensão da realidade; b) na visualização dos limites daquilo que se gestou no passado e que segue atuando no presente, muitas vezes sob a aura da objetividade; e c) na retomada de possibilidades existenciais já abertas no passado, mas que depois caíram no esquecimento ou foram distorcidas pelo repasse superficial delas através de inúmeras gerações. Nesse sentido, nosso recurso crítico à tradição, possibilitado pela Destruktion heideggeriana, conduz-nos ao autoexame crítico de nossas próprias pressuposições culturais e intelectuais, abrindo-nos, ao mesmo tempo, a possibilidade de reter, atualizando-as, experiências existenciais libertadoras que a tradição nos oferece e que permaneceram encobertas, inclusive, pelo ofuscamento de nossa própria visão de mundo, pelo cisco que turva nossa própria visão.

$\mathrm{Na}$ conferência Língua de tradição e língua técnica, pronunciada na década de 1960, Heidegger agrega à retomada desconstrutiva da tradição um pesado discurso contra a instrumentalização da linguagem que avança lado a lado com o desenvolvimento técnico-científico, sobretudo por meio da cibernética (o que chamamos hoje, grosso modo, de informática). O filósofo argumenta que, conforme avança o uso e a compreensão da linguagem como instrumento de troca e comunicação, a língua torna-se sinônimo de informação. "O único carácter da língua que permanece na informação é a forma abstracta da escrita, que é transcrita nas fórmulas de uma álgebra lógica. A univocidade dos sinais e das fórmulas, que é necessariamente exigida por isto, assegura a possibilidade de uma comunicação certa e rápida" (HEIDEGGER, 1995, p. 36). Sobre esses princípios tecno-calculadores da linguagem é que repousa a possibilidade de construção e funcionamento dos computadores. E é em relação a sua pertinência a essas máquinas que a linguagem passa a ser concebida: "O género (Art) e o estilo da língua determinam-se a partir das possibilidades técnicas de produção formal de sinais, produção que consiste em executar uma série contínua de decisões sim-não com a maior rapidez possível" (HEIDEGGER, 1995, p. 36). O problema disso está no fato de que a linguagem, quando convertida em informação, perde o seu poder essencial de mostrar e fazer ver aquilo que ainda não foi mostrado e não foi visto. Enquanto instrumento de informação, a linguagem apenas aponta para aquilo que de alguma forma já se mostrou e já foi visto. Mas não é só isso: uma vez que a relação do homem com o ente que o rodeia e consigo mesmo repousa sobre o que é mostrado e visto a cada vez, Heidegger alerta que "a agressão da língua técnica sobre o carácter próprio da língua é ao mesmo tempo uma ameaça contra a essência mais própria do homem" (1995, p. 37-38). A forma sugerida de reagir a essa ameaça é a recuperação da tradição por meio da língua "natural".

Aquilo que é aqui nomeado por língua "natural" - a língua corrente não tecnicizada - nós denominámo-la no título da conferência por língua da tradição (überlieferte Sprache). Tradição não é uma pura e simples outorga, mas a preservação do inicial, a salvaguarda de novas possibilidades da língua já falada. É esta que encerra o informulado e o transforma em dádiva. A tradição da língua é transmitida pela própria língua, e de tal maneira que exige do homem que, a partir da língua conservada, diga de novo o mundo e por aí chegue ao aparecer do ainda-nãoapercebido. (HEIDEGGER, 1995, p. 40)

Se compreendemos bem o argumento de Heidegger, o que ele está nos dizendo é que quando negligenciamos a língua nativa, na qual as palavras tem uma história e, através dessa história, apontam para a contingência da articulação do sentido de nosso mundo, também negligenciamos a possibilidade de rompermos com a articulação de sentido que mantém o status quo atual e (consequentemente) terminamos presos aos modos de vida vigentes. O ainda-não de mundos possíveis não pode ser alcançado por meio de uma língua técnica, mas somente por meio de uma língua natural que preserva em suas palavras a ambiguidade de sentidos historicamente constituídos, 
justamente aquilo que o processo de destruição/ desconstrução da tradição busca liberar.

Uma visualização mais concreta do modo pelo qual o caráter formativo da desconstrução se insere nos processos educativos pode ser conquistada pela perspectiva do fazer filosófico. Para isso, nos valemos de uma concepção de filosofia cujo propósito, em linha com o pensamento de Heidegger, é nos tornar novamente livres para ouvir a força metafórica contida nas palavras, antes de elas serem estabilizadas como verdades literais pelo uso corrente da linguagem. Assim, a luta da filosofia é para que não nos deixemos absorver a tal ponto no uso literal da linguagem que acabemos por nos esquecer da possibilidade da poesia - da inovação e da transformação do sentido. Afinal, se, como dissemos, nosso mundo é articulado por meio de palavras, então a estabilização do sentido das palavras leva à estagnação do mundo.

Contrastando com uma educação de tendência conteudista, focada na transmissão de conhecimentos e no desenvolvimento de competências e habilidades (geralmente, daquelas economicamente pertinentes), Heidegger (1997, p. 20) não vê problemas em admitir que é inteiramente correto dizer que "a filosofia não serve para nada". O que está errado, acrescenta ele, é pensar-se que assim se tenha completado definitivamente o juízo sobre a filosofia; pois, há ainda um pequeno aditamento que se deve apresentar sob a forma de uma contrapergunta: "se, já que nós nada sabemos fazer com a filosofia, não saberá ela fazer algo connosco [sic], caso nos deixemos envolver com ela"? (HEIDEGGER, 1997, p. 21). O filósofo sugere, assim, que o valor da filosofia, que não está obviamente em sua utilidade pragmática, reside na transformação que resulta do envolvimento com ela. A filosofia transforma porque ela lida com o extra-ordinário, de forma extra-ordinária. "Filosofar é questionar o extraordinário", de modo que "o próprio questionar está fora de ordem" (HEIDEGGER, 1997, p. 21). O estranhamento resultante do filosofar mobiliza nosso ser no mundo, nosso Dasein, e o transforma na e para a relação com esse mundo.

Heidegger sustenta, então, que a filosofia mostra um modo de viver que não se deixa mover pela pressa utilitária de buscar uma resposta para problemas que na maioria das vezes são impostos pela sociedade à educação e às instituições formais de ensino, sem que ao menos permitisse a elas o tempo necessário para investigar a origem de tais problemas e, menos ainda, o envolvimento dos sujeitos educacionais no próprio processo de descoberta e busca de solução de problemas. ${ }^{6}$ Desse modo, a aparente "inutilidade" exigida por Heidegger à filosofia, pode ser ampliada como força intelectual crítica contra

\footnotetext{
${ }^{6}$ Para um acrítica bem justificada à formação por competências baseada na solução de problemas, ver R. Wiechmann (2013).
}

as reformas universitárias mundiais, inclusive contra as própria reformas da universidade alemã, e o reducionismo que elas provocam da Bildung, concebendo-a tão somente como formação por competências profissionais especializadas, voltadas para a satisfação do mercado de trabalho. Essa redução da formação geral e cultural mais ampla à formação por competências está, como mostrou Lutz Koch, no bojo do amplo processo de transformação da universidade em grande empresa de negócios, conduzida pelo modelo do gerenciamento empresarial $(\mathrm{KOCH}, 2001)$. De outra parte, o esforço de reabilitação da Bildung ancorado no modelo crítico da Destruktion heideggeriana, ao abrir a possibilidade de pensar a própria Bildung no sentido pós-humanista, evita o risco de que tal reabilitação signifique um retorno, pela porta dos fundos, dos traços metafísicos destrutivos (no sentido negativo) inerentes à noção clássica da Bildung (DALBOSCO; DORO, 2019).

Gostaríamos de insistir aqui na ideia de que uma forma extra-ordinária de confronto com a realidade, que oferece uma armadura conceitual consiste ao sujeito contemporâneo, se dá por meio da ocupação com textos filosóficos e pedagógicos clássicos, não somente para saber sobre eles, mas principalmente para aprender o sentido profundo dos conceitos que neles operaram e, principalmente, para continuar a pensar adiante o que por meio deles se pensou. Se bem conduzido, compreendido nos termos de um exercício de si por meio da lógica clandestina de leitura perspicaz e escrita aberta (FLICKINGER, 2010), resulta na transformação formativa dos envolvidos, pois, ao entregar-se corajosamente ao sofrimento da leitura de uma obra clássica, certamente ninguém mais permanece igual ao que era. ${ }^{7}$ É precisamente nesse sentido que entendemos que cabe à filosofia auxiliar a pensar o espaço formativo não apenas como transmissor de saber/fazer, mas como movimento intelectual de uma boa experiência formativa. Contudo, para que isso aconteça, a filosofia precisa desvencilharse criticamente de pressuposições metafísicas e pensar-se em um horizonte pós-humano, sem abrir mão, obviamente, de sua postura originária de provocar nos seres humanos o espanto diante de si mesmos e do mundo. Com isso, ela certamente pode oferecer, então, um diagnóstico do tempo presente, delineando, também, uma perspectiva futura aberta aos acontecimentos históricos imprevisíveis e às fragilidades humano-sociais. Como Destruktion, ao possibilitar uma reelaboração crítica da tradição, a

\footnotetext{
${ }^{7}$ Foi com esse espírito que a tradição filosófico-pedagógica antiga, como mostrou Michel Foucault (2004, p. 144-162), certamente também influenciado pelo modelo desconstrutivo heideggeriano, atribui à leitura e escrita seu mais alto significado, ou seja, como modo genuíno de aprender a morrer.
} 
filosofia torna-se também uma força crítica que nos auxilia a pôr em questão "os ciscos" que embaralham nossa própria visão de mundo e, com isso, encurtam extraordinariamente nosso campo de ação. Não é mais, contudo, a filosofia em sua frigidez conceitual congelada, mas sim, em sua aliança poética com a metáfora, que se transforma nessa força removedora dos ciscos que estão em nosso olho, abrindo-nos a visão para outros horizontes possíveis.

Assim, a relação entre filosofia e formação ganha contornos bem definidos com base na crítica à metafísica proposta por Heidegger. O pensador alemão nos alerta para que a busca pelo sentido originário das palavras não recaia em uma simples dedução, mas que abra possibilidades distintas de pensar e ser, pois mantendo-se dogmática, ela ignora a temporalidade e historicidade do ser, elevando o próprio ser humano à condição insustentável de sujeito onipotente. O risco do processo formativo manter-se dogmático e metafísico, se dá pela possibilidade do ser humano ficar aprisionado no sistema vigente, ignorando a ambiguidade do pensamento metafísico. Por isso, tal Destruktion serve também para ver a educação moderna não só como um projeto determinista, marcado pela teleologia fechada, que impede a qualquer custo a posição ativa e livre do sujeito educacional. Inspirando-se no modelo de superação da metafísica, sem contudo precisar decretar seu próprio fim, a filosofia pode ler a contrapelo os projetos modernos de educação e seus vários modelos escolares, distanciando-se criticamente deles, mas mantendo ao mesmo tempo o que pode ser preservado. Assim, a crítica com inspiração na Destruktion heideggeriana pode preservar, atualizando em sentido pós-humanista, conceitos de uma longa tradição filosófico-pedagógica moderna, como perfectibilidade (Rousseau), multiplicidade do interesse (Herbart) e plasticidade (Dewey), colocando-os a favor de uma defesa de educação pública e democrática.

Em síntese, da forma de pensar baseada na Destruktion, pode resultar insights importantes para uma teoria educacional crítica ao modelo educacional vigente que, orientado exclusivamente pelo neoliberalismo mercadológico, concebe e dirige a educação pelo gerenciamento empresarial, impondo à educação critérios extra-formativos, como concorrência desleal, eficácia pragmática e lucratividade a qualquer preço. Sendo assim, as instituições formais de ensino, incluindo nelas principalmente as instituições de ensino superior, veem-se duplamente privatizadas: de modo mais amplo, pela governança neoliberal e; simultaneamente, de modo mais específico, pelo empreendedorismo individualista que toma conta do cotidiano educacional. Vê-se, no espaço outrora formativo, uma fonte de lucro e a avaliação de sujeitos moldada por resultados que não contemplam suas individualidades e suas histórias. Obviamente que a Destruktion não resolve todos os problemas, mas, como procuramos mostrar, no duplo movimento que provoca, torna-se uma poderosa pinça a remover o cisco do olhos dos sujeitos contemporâneos.

\section{Conclusão}

O retorno à origem das palavras e a ressignificação resultante desse movimento significam, para Heidegger, não apenas um trabalho de reconstrução histórica e etimológica, mas sim uma busca pelo sentido e, em especial, pela verdade (desvelamento) do mundo. Tal busca pode ser compreendida como uma forma de estar e se fazer presente, de participar e se constituir como ser, diferente de apenas se deixar guiar pelo senso-comum ou pelo paradigma norteador vigente. Para tanto, Heidegger reivindica um diálogo constante e aberto com a tradição, o que constitui, para ele, a própria força do pensamento.

Conforme mencionado na introdução deste trabalho, a proposta heideggeriana de pensar 0 conceito de verdade como $\dot{\alpha} \lambda \dot{\eta} \theta \varepsilon ı$ e não como veritas, que na tradição latina remete à noção de correspondência, auxilia a abrir espaço para o desvelamento do indivíduo e do mundo enquanto projeto a ser assumido autenticamente por cada um. A tarefa de tornar o manuseio das palavras flexível inserese nesse contexto. Romper com o enrijecimento da linguagem é romper, ao mesmo tempo, com o enrijecimento da existência. Isso porque a existência e a realidade, não são para o ser humano coisas préprogramadas, que devem seguir um destino imutável e não dialógico. E durante o seu viver que o ser humano vai elegendo suas possibilidades, formando suas crenças, optando por uma forma de vida. Tais atividades tornam-se cada dia mais complexas, na medida em que a sociedade e até mesmo a educação parecem ter definido previamente o rumo, as respostas e os indicativos de vida a serem assumidos por cada um, por mais diferentes que indivíduos sejam entre si. Por esse caminho, o destino do ser humano pode ser o do inevitável empobrecimento das artes, do enfraquecimento das experiências, do consumo desenfreado, do esquecimento do pensar, mas acima de tudo, da anulação de si mesmo, da semiformação.

Processos de socialização que se limitam a reproduzir como naturais modos de vida herdados da tradição fazem com que os indivíduos abdiquem da responsabilidade de escolher os projetos para a sua vida e para o seu mundo. A existência perde autenticidade quando fica presa em um horizonte de sentido de tal forma cristalizado. $\mathrm{Na}$ atualidade, sedimenta-se cada vez mais a perspectiva técnica, na qual sobressai a figura do indivíduo eficiente, capaz de solucionar problemas de forma imediata, que deve se 
moldar às demandas da ocasião, sob o risco constante de se tornar obsoleto, como se fosse apenas mais uma peça substituível de um sistema autônomo que independe das decisões humanas. A falta de experiências, a indisposição para discussões, a constante busca de utilidade de tudo e de todos, tanto no meio político, acadêmico e social, promovem um modo de vida individualista em que não se tem espaço para a reflexão e para a experiência.

A recuperação destrutiva/desconstrutiva da tradição linguística e das formas de ser podem funcionar como um antídoto poderoso contra a naturalização dessa perspectiva reducionista do ser humano e da sociedade. Tentamos mostrar como isso pode ocorrer por meio da filosofia em sua dimensão eminentemente formativa. A metódica Destruktion heideggeriana pode se mostrar potente, enquanto crítica educacional, para reconstruir o sentido originário dos conceitos formativos, que fora esquecido ou deturpado pela imposição de forças sociais, econômicas e culturais dominadoras. Neste contexto, se torna sintomático, como procuramos mostrar nesse ensaio, o modo instrutivo com o qual o método da Destruktion pode operar sobre o próprio sentido da Bildung, oferecendo a possibilidade do diálogo crítico com a tradição, no sentido de criticar a noção de formação humana, preservando sua dupla potencialidade reflexiva: como autoexame crítico do sujeito sobre si mesmo (autoformação) e como crítica cultural do reducionismo atual que é imposto de fora à própria educação.

Deste modo, profundamente aliada com outras fortes expressões culturais, como a literatura e a poesia, a filosofia constitui importante porta de acesso à riqueza cultural de uma tradição que precisa ser constantemente desconstruída para que não se esvaia em significações enrijecidas e vazias. Enquanto dimensão formativa, a filosofia auxilia a própria educação a recuperar criticamente a historicidade de seus conceitos, ao mesmo tempo que, imbricando-se com experiências formativas proporcionadas pelo campo educacional, ela (a filosofia) pode apreender ainda mais sobre a concretude dos modos humanos de agir e julgar. Em tempos de predominância do apelo à eficiência e eficácia técnico-produtiva, deveríamos fazer, enquanto governança educacional pública, o movimento exatamente o contrário, em vez de eliminar as Humanidades, incluí-las ainda mais em todos os níveis do currículo educacional, desde a Educação Básica até a Pós-Graduação. Pois, embora não seja só monopólio das Humanidades, inegavelmente são elas que com maior força nos descortinam o sentido e a importância do trabalho da Destruktion para a reconstrução crítica de nossa própria Weltanschauung.

\section{References Références Referencias}

1. BIESTA, Gert. Bildung and Modernity: The Future of Bildung in a World of Diference. Studies in Philosophy and Education, vol. 21, issue 4-5, p. 343351, Jul. 2002.

2. DALBOSCO, Cláudio A.; DORO, Marcelo J. Ontologia da formação pós-humanista em Heidegger e Foucault. ETD: Educação Temática Digital, v. 21, p. 63-83, 2019. Disponível em https:// periodicos.sbu.unicamp.br/ojs/index.php/etd/article/ view/8650840/18997. Acesso em: 21 jun. 2021.

3. DE CASTRO, Fábio F. Linguagem e comunicação em Heidegger. Galaxia (São Paulo, Online), n. 27, p. 85-94, jun. 2014. Disponível em http://dx.doi.org/10. 1590/1982-25542014116332. Acesso em: 21 jun. 2021.

4. EILAND, Howard. Heidegger's Etymological Web. Boundary 2, v. 10, n. 2, p. 39-58, Winter, 1982.

5. FLICKINGER, Hans-Georg. A caminho de uma pedagogia hermenêutica. Campinas, SP: Autores Associados, 2010.

6. FOUCAULT, Michel. Ditos \& Escritos V: Ética, Sexualidade, Política. Rio de Janeiro: Forense Universitária, 2004.

7. FRANK, Manfred. Das Sagbare und das Unsagbare. Studien zur deutsche-französischen Hermeneutik und Texttheorie. Frankfurt am Main: Suhrkamp, 1990.

8. GADAMER, Hans-Georg. Hermenêutica em retrospectiva: Vol. 1 - Heidegger em retrospectiva. 2. ed. Petrópolis: Vozes, 2007.

9. GOERGEN, Pedro. Bildung ontem e hoje: restrições e perspectivas. Revista Espaço Pedagógico, v. 24, n. 3, p. 437-451, 19 dez. 2017. Disponível em https://doi.org/10.5335/rep.v24i3.7758. Acesso em: 21 jun. 2021.

10. GOETHE, Johann W. von. De minha vida: poesia e verdade. São Paulo: Editora UNESP, 2017.

11. HABERMAS, Jürgen. Discurso filosófico da modernidade. São Paulo: Martins Fontes, 2000.

12. HEIDEGGER, Martin. ¿Qué significa pensar? Buenos Arires: Editorial Nova, 1964.

13. HEIDEGGER, Martin. A questão da técnica. In: HEIDEGGER, Martin. Ensaios e conferências. Petrópolis: Vozes, 2006, p. 11-38.

14. HEIDEGGER, Martin. Carta sobre o humanismo. 2. ed. rev. São Paulo: Centauro, 2005.

15. HEIDEGGER, Martin. Conferências e escritos filosóficos. São Paulo: Nova Cultural, 1999. (Coleção Os pensadores)

16. HEIDEGGER, Martin. Contribuições à filosofia (Do acontecimento apropriador). Rio de Janeiro: Via Verita, 2015.

17. HEIDEGGER, Martin. Introdução à metafísica. Lisboa: Instituto Piaget, 1997. 
18. HEIDEGGER, Martin. Língua de Tradição e Língua Técnica. Lisboa: Vegas, 1995.

19. HEIDEGGER, Martin. Os problemas fundamentais da fenomenologia. Petrópolis: Vozes, 2012.

20. HEIDEGGER, Martin. Sein und Zeit. Tübingen: Max Niemeyer, 1986.

21. INWOOD, Michael. Heidegger e sua linguagem. In: INWOOD, Michael. Dicionário Heidegger. Rio de Janeiro: Jorge Zahar Editor, 2002, p. XVI-XXIV.

22. $\mathrm{KOCH}$, Lutz. Von der Bildungsanstalt zum Grossbetrieb. In: Vierteljahrschrift für wissenschaftliche Pädagogik, H. 3/2001, S. 429-445.

23. MARROU, Henri-Irénée. História da educação na antiguidade. São Paulo: EPU, 1990.

24. NIETZSCHE, Friedrich. Kritische Studienausgabe. Band 6. München: DTV, 1999.

25. RORTY, Richard. Ensaios sobre Heidegger e outros. Lisboa: Instituto Piaget, 1999.

26. ROUSSEAU, Jean-Jacques. Emílio ou da Educação. São Paulo: Bertrand Brasil, 1992.

27. STEIN, Ernildo. A questão do método na filosofia: um estudo do modelo heideggeriano. 2. ed. Porto Alegre: Movimento, 1983.

28. WIECHMANN, Ralf. Zur Verabsolutierung des Problemlösens im Kompetenzkonzept und ihre Folgen. Vierteljahrschrift für wissenschaftliche Pädagogik, Heft 1, 2013, S. 124-147. 